\title{
Publisher Correction: Establishing long-term nitrogen response of global cereals to assess sustainable fertilizer rates
}

Hans J. M. van Grinsven (D), Peter Ebanyat (D), Margaret Glendining (D), Baojing Gu (D), Renske Hijbeek, Shu Kee Lam (D), Luis Lassaletta, Nathaniel D. Mueller (D), Felipe S. Pacheco (D), Miguel Quemada (D), Tom W. Bruulsema (D),

Brian H. Jacobsen and Hein F. M. ten Berge (iD

Correction to: Nature Food https://doi.org/10.1038/s43016-021-00447-x, published online 31 January 2022.

In the version of this article originally published, there were errors in Fig. 7 and equation (4). In Fig. 7, the center heading, now reading "Food plate to farm gate price ratio $=3$ " originally read, in part, "ratio $=1$." In equation 4 , now reading " $N \%=1.873+\left(3.26 \times 10^{-3} \times N_{\text {av }}\right)-$ $\left(6.20 \times 10^{-2} \times Y_{\max }\right)\left(R^{2}=0.743, N=224\right)$," an extraneous minus symbol was present before "6.20." Further, in equations (5), (7) and (8), extraneous minus signs within parentheses following minus operators were removed. And in equation (7), in the terms now reading " $\left(\mathrm{d} C_{\text {fixed }}\right)$ " and " $\left(\mathrm{d} C N_{\text {pollut }_{i}}\right)$," the letter " $C$ " originally appeared as " $P$." The errors have been corrected in the HTML and PDF versions of the article.

Published online: 16 February 2022

https://doi.org/10.1038/s43016-022-00475-1

(๑) The Author(s), under exclusive licence to Springer Nature Limited 2022 